\title{
Microstructure and Mechanical Properties of AZ31 Mg Alloy Fabricated by Pre-compression and Frustum Shearing Extrusion
}

\author{
Kun Sheng ${ }^{1,2} \cdot$ Li-Wei Lu $^{1,2} \cdot$ Yao Xiang ${ }^{2} \cdot$ Min $\mathrm{Ma}^{2} \cdot$ Zhong-Chang Wang ${ }^{3}$ \\ Received: 20 July 2018/Revised: 6 October 2018/Published online: 13 November 2018 \\ (C) The Chinese Society for Metals and Springer-Verlag GmbH Germany, part of Springer Nature 2018
}

\begin{abstract}
The AZ31 Mg alloys were processed by 6\% pre-compression and frustum shearing extrusion at various temperatures, and the microstructure, texture and mechanical properties of the resulting alloys are systematically investigated. The results show that the grain size monotonically increases from 6.4 to $12.6 \mu \mathrm{m}$ and the texture intensity increases from 6.7 to 9.6 with the increase in the extrusion temperature. The combining effect of the pre-twinning and the frustum shearing deformation is found to contribute to the development of the weak basal texture in $\mathrm{Mg}$ alloys. The $\mathrm{Mg}$ alloy sheet produced at the extrusion temperature of $563 \mathrm{~K}$ exhibits excellent mechanical properties. The yield strength, ultimate tensile strength and elongation for the extruded alloys are $189.6 \mathrm{MPa}, 288.4 \mathrm{MPa}$ and $24.9 \%$, respectively. Such improved mechanical properties are comparable or even superior to those of the alloys subjected to other deformation techniques, rendering the pre-compression and frustum shearing extrusion a promising way for further tailoring properties of $\mathrm{Mg}$ alloys.
\end{abstract}

Keywords AZ31 magnesium alloy · Frustum shearing extrusion · Microstructure · Mechanical property · Dynamic recrystallization

\section{Introduction}

Magnesium alloys are the lightest metallic materials for industrial applications with increasing needs due to their low density, high specific strength, good damping characteristics and stable machinability [1-3]. For instance, they are widely used in the fields of aerospace, military, automotive and electronic industry [4-6]. However, in view of

Available online at http://link.springer.com/journal/40195

Li-Wei Lu

cqullw@163.com

$\triangle$ Zhong-Chang Wang

zhongchang.wang@inl.int

$1 \quad$ Hunan Provincial Key Laboratory of High Efficiency and Precision Machining of Difficult-to-Cut Material, Hunan University of Science and Technology, Xiangtan 411201, China

2 College of Materials Science and Engineering, Hunan University of Science and Technology, Xiangtan 411201, China

3 Department of Quantum Materials Science and Technology, International Iberian Nanotechnology Laboratory (INL), Av. Mestre José Veiga s/n, 4715-330 Braga, Portugal the structure of hexagonal close-packing lattice, magnesium exhibits less independent slip systems at room temperature and its alloys still show poor ductility and low strength, which greatly restrict their widespread applications [7, 8]. According to Hall-Petch relationship, grain refinement is an effective method to enhance strength and ductility of magnesium alloys [9]. Therefore, various methods have been developed to improve the mechanical properties of magnesium alloys via grain refinement during the last two decades. Among these techniques, equal channel angular pressing (ECAP) is regarded as one of the most efficient processing techniques for the production of high-performance $\mathrm{Mg}$ alloys with grain size below $1 \mu \mathrm{m}$ $[10,11]$. However, ECAP is not widely used in industrial practices due to some limitations [12-14]. Particularly, ECAP usually requires 4-10 passes to obtain a stable uniform grain size, which suggests that ECAP is not a continuous process, making it difficult for industrial applications. Recently, several methods have been also reported to refine the grain and weaken the texture by asymmetric porthole die extrusion [15], asymmetric extrusion [16] and optimizing the extrusion die angles [17]. The results show that mechanical properties of extruded sheets improvement were ascribed to an introduction of 
large effective strain gradient throughout the normal direction by these effective methods.

Several strengthening methods can be utilized to enhance the strength of $\mathrm{Mg}$ alloys, including solid-solution hardening, aging hardening, refinement hardening and dislocation hardening. For the hexagonal close packed (HCP) Mg alloys, the strength of special directions can also be enhanced by texture control owing to the strong plastic anisotropy and texture hardening. Pre-twinning can result in the change in grain orientation and twin lamellae, and subdivide the original grains. Thus, pre-twinning holds a potential for generating refinement hardening and texture hardening [18, 19]. Recently, it has been reported that twins induced by pre-deformation play a major role in subsequent deformation in Mg alloys. Dynamic recrystallization (DRX) of $\mathrm{Mg}$ alloys is also greatly affected by deformation twins [20]. Moreover, for the as-cast $\mathrm{Mg}$ alloys, the $\{10-12\}$ extension twins can be easily generated by pre-compression along an appropriate direction at room temperature [21, 22]. Therefore, pre-twinning is considered as a new strategy to develop low-cost and high-performance magnesium alloys. However, there is little further study on the effects of large pre-compression on hot extrusion deformation.

In this work, we first conduct pre-compression experiments and then extrude using frustum shearing deformation at various temperatures. It should be noted that the texture and mechanical properties of $\mathrm{Mg}$ alloys sheet have been improved greatly after the $6 \%$ pre-compression and frustum shearing extrusion in our previous work. The focus of this work is aiming to investigate the microstructure evolution, texture variation and mechanical properties in detail during extrusion at various temperatures.

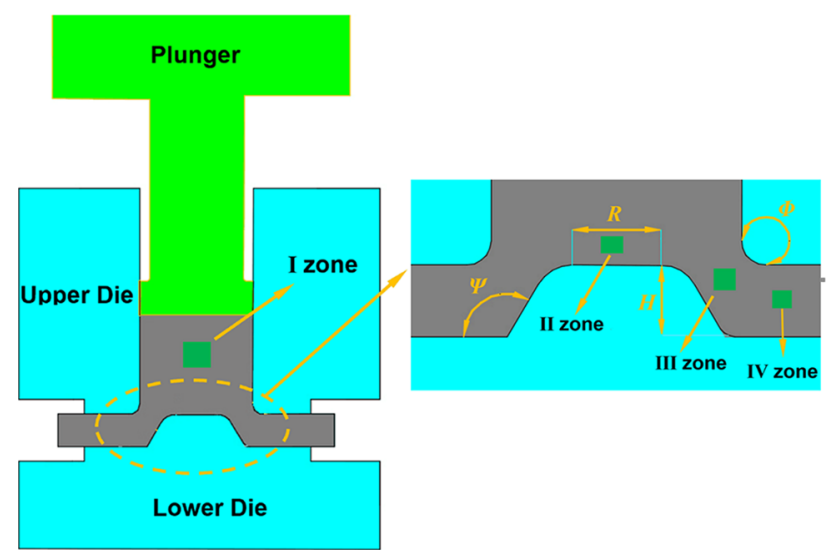

Fig. 1 Schematic of the frustum shearing extrusion die

\section{Experimental}

Schematic of the frustum shearing extrusion die is shown in Fig. 1. The die can be divided into four parts labeled as I, II, III and VI, which represented the upsetting zone, the frustum zone, the corner shearing zone and the eventual forming zone, respectively. The extrusion die consisted of two equal sectional dies that were clamped by screws, each of which had a half shearing structure, and all parts of the die were made of the H13 steel. In addition, the cavity parameters of steel dies were as follows: The diameter and length of vertical channel were $36 \mathrm{~mm}$ and $70 \mathrm{~mm}$, respectively, $\psi$ was $120^{\circ}$ and $\Phi$ was $90^{\circ}$, and the frustum height and diameter were $2.5 \mathrm{~mm}$ and $14 \mathrm{~mm}$, respectively, and the width and thickness of eventual forming channel were $25 \mathrm{~mm}$ and $2 \mathrm{~mm}$, respectively. The experimental billets are divided into two parts. Generally, the different die angles $(\psi$ and $\Phi)$ can provide different effective strain. In this experiment, it is expected the upper surface through one right angle shearing deformation and the under surface through two obtuse angles, so that the sheets can produce uniform strain. Compared with other deformation methods, the key advance of this deformation can accumulate large strain to completely trigger DRX and even crush coarse grains during the extrusion process.

The $\mathrm{Mg}$ alloys used has a chemical composition (in mass $\%$ ) of $3 \% \mathrm{Al}, 1 \% \mathrm{Zn}, 0.5 \% \mathrm{Mn}, 0.0075 \% \mathrm{Si}, 0.003 \%$ $\mathrm{Fe}, 0.0025 \% \mathrm{Cu}, 0.0007 \% \mathrm{Ni}$ and $\mathrm{Mg}$ (in balance). Before extrusion, the as-cast $\mathrm{Mg}$ alloys were first homogenized at $673 \mathrm{~K}$ for $15 \mathrm{~h}$ and then cut into experimental billets with dimensions of $\Phi 35 \mathrm{~mm} \times 40 \mathrm{~mm}$. The $6 \%$ pre-compression test was carried out on a CMT5105 test machine at a constant rate of $10^{-3} \mathrm{~s}^{-1}$.

The samples and the dies were fully lubricated with a lubricant of $75 \mathrm{wt} \%$ oil and $25 \mathrm{wt} \%$ graphite. The extrusion experiments were conducted at $563 \mathrm{~K}, 603 \mathrm{~K}, 643 \mathrm{~K}$ and $683 \mathrm{~K}$ with an extrusion speed of $1 \mathrm{~mm} \mathrm{~s}^{-1}$ and extrusion ratio of 10.18 , respectively. All the products were naturally cooled in air after extrusion. Samples were machined into blocks with dimensions of $8 \mathrm{~mm}$ in extrusion direction (ED) and $6 \mathrm{~mm}$ in normal direction (ND) to investigate the microstructure. The microstructures of the samples were observed from ED-ND plane by optical microscopy (OM), X-ray diffraction (XRD), scanning electron microscopy (SEM) and electron backscatter diffraction analysis (EBSD). The macro texture was measured by X-ray diffraction (XRD, Rigaku D/MAX$2500 \mathrm{PC}$ ) with $\mathrm{Cu}-\mathrm{K} \alpha$ radiation at $40 \mathrm{kV}$ and $30 \mathrm{~mA}$ and a scan rate of $0.03 \mathrm{deg}^{-1}$ in a $2 \theta$ range of $10^{\circ}-90^{\circ}$. The specimens for EBSD analysis were primary polished (grinding on $\mathrm{SiC}$ papers of grit size 280,600, 800, 1000, $1200,2000)$ followed by electrolytic polishing at a voltage 
of $20 \mathrm{~V}$ for $\sim 50 \mathrm{~s}$ at $-15{ }^{\circ} \mathrm{C}$ with $\mathrm{AC} 2$ electrolyte. The EBSD measurement was taken at the operating voltage of $20 \mathrm{kV}, 14.5 \mathrm{~mm}$ working distance and a $70^{\circ}$ tilt. EBSD data were analyzed by means of Channel 5 software.

The tensile properties were measured using nonstandard tensile specimens with a gauge size of $5 \mathrm{~mm}$ in width and $35 \mathrm{~mm}$ in length. All the specimens had an axis along the extrusion direction. The tensile tests were performed at a constant strain rate of $2 \times 10^{-3} \mathrm{~s}^{-1}$.

\section{Results and Discussion}

\subsection{Optical Microstructure}

Figure 2 shows the optical microstructures of AZ31 Mg alloy before and after $6 \%$ pre-compression. The grains in homogenized $\mathrm{Mg}$ alloy are coarse, and the average grain size is measured to be about $213 \mu \mathrm{m}$ (Fig. 2a). There are a large number of $\{10-12\}$ twins observed within almost all of the grains after $6 \%$ pre-compression at room temperature (Fig. 2b), indicating that twinning mode plays an important role in pre-compression process of $\mathrm{Mg}$ alloys.

The microstructures of $\mathrm{Mg}$ alloys sheet fabricated by pre-compression and frustum shearing extrusion at extrusion temperature ranging from 563 to $683 \mathrm{~K}$ are shown in Fig. 3. The average grain size of extruded $\mathrm{Mg}$ alloy sheets are estimated to be $6.4,7.4,9.3$ and $12.6 \mu \mathrm{m}$, thus implying that this technique can effectively refine the grain size due to the DRX, and the extrusion temperature is important for regulating and controlling microstructure. Although the grains grow gradually with the increase in temperature, they are refined significantly in comparison with the homogenized cases. Closer observation reveals that a few elongated grains are shown in Fig. 3a, which indicates that incomplete DRX takes place during the extrusion process at lower temperature $(563 \mathrm{~K})$. Even so, the average grain size is still less than $8 \mu \mathrm{m}$, proving that $563 \mathrm{~K}$ is also suitable for this technique.
With the increase in the extrusion temperature $(603,643$ and $673 \mathrm{~K}$ ), the grain size increases, and there are some coarse grains in local regions, which is mainly attributed to the grain growth at elevated temperature and the occurrence of second recrystallization inside some grains [23-25]. Overall, extrusion temperature plays an important role in DRX and DRXed grains coarsening; once the grain growth rate is greater than DRX nucleation rate, the grains will coarsen during hot extrusion process.

\subsection{EBSD Analysis}

Figure 4 shows the EBSD map and twin distribution of $\mathrm{Mg}$ alloy sheets in III zone at $563 \mathrm{~K}$. The microstructure consists of a few deformed parent grains and recrystallized grains, which are determined by the criterion that deformed and recrystallized grains show high and low misorientations, respectively $[26,27]$. During the extrusion process, the grains are distorted and elongated due to the intense shearing effect and the substructural boundaries formed in the alloys, respectively. As the extrusion proceeds, most of the substructural boundaries will disappear and become long strip or tiny recrystallized grains. To reveal the grain refinement mechanism, typical regions (A and B) with different morphologies are shown in Fig. 4a, c, and there are four typical regions of $A_{1}, A_{2}, A_{3}$ and $A_{4}$ in A. DRX grains in regions $A_{1}$ and $A_{2}$ are formed at the tip of the $\{10-12\}$ tension twins, while DRX grains in regions $A_{3}$ and $\mathrm{A}_{4}$ are developed grain boundaries. Therefore, the twin could be classified as two types according to their function of triggering DRX, some twin boundaries are easier to slip, the accumulated dislocation density is lower, and only the twin tip can favor for triggering DRX, as shown in regions $A_{1}$ and $A_{2}$. With further deformation going on (IV zone), it will increase the dislocation density at the twin boundaries, thus providing more energy to induce DRX. Besides, other twin boundaries are easier to gather high dislocation density, fully promoting the DRX formation, and the DRX would grow to subdivide the twin into fine grains, as shown
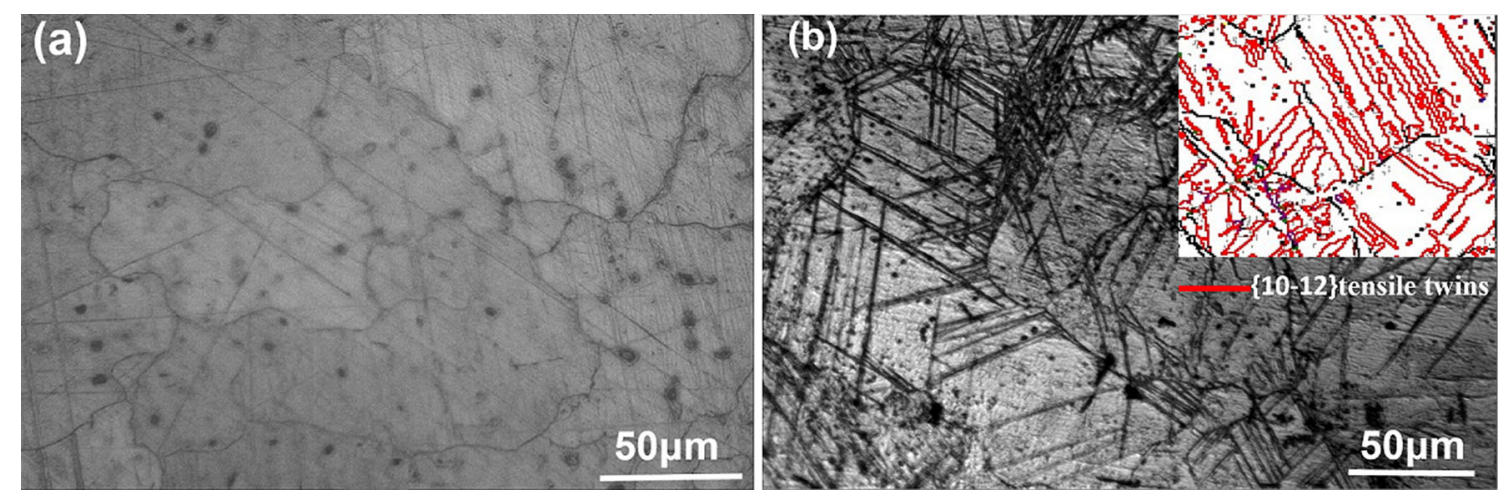

Fig. 2 Optical micrographs of AZ31 Mg alloy: a as-cast, b pre-compression 6\% 

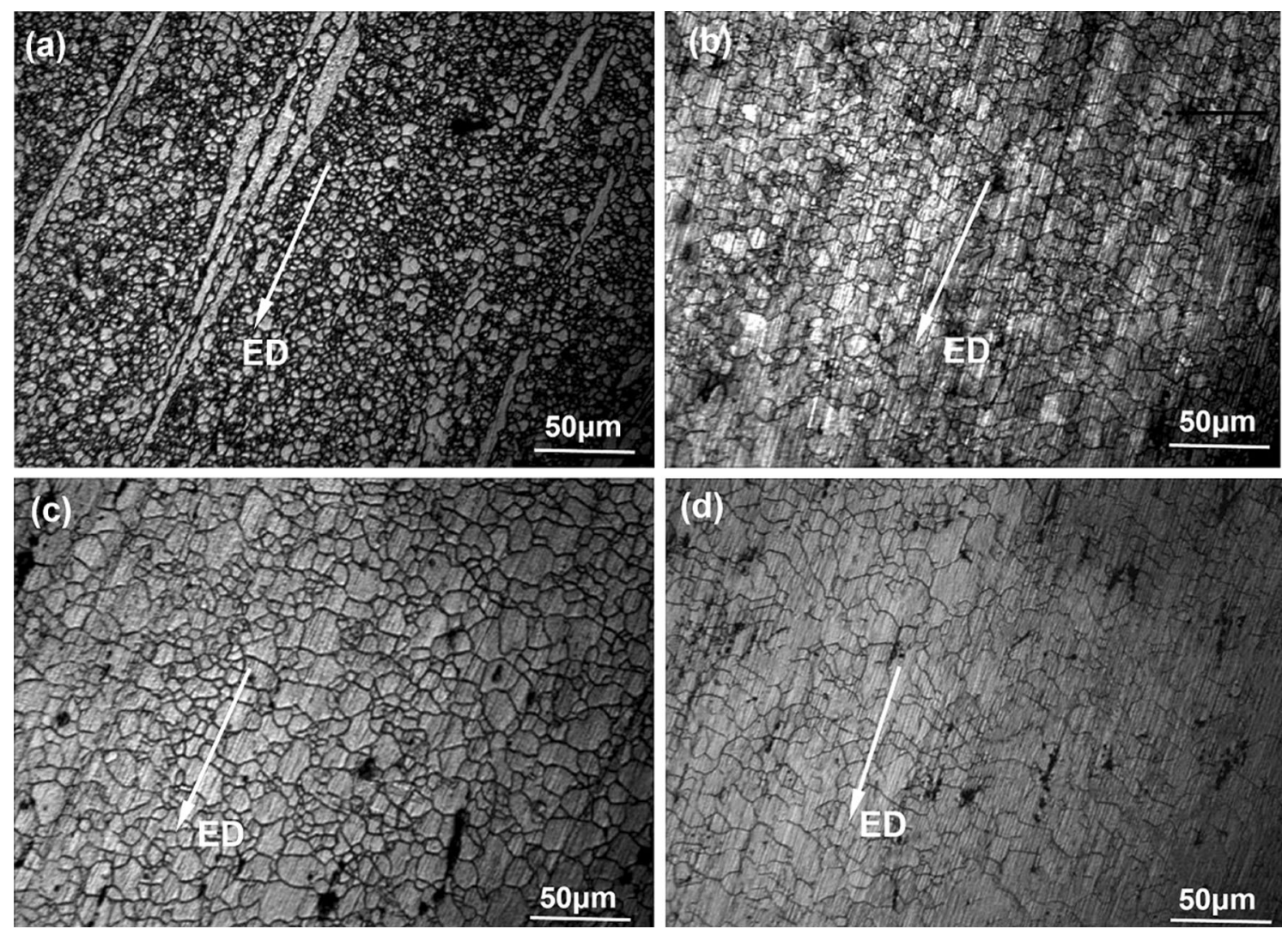

Fig. 3 Optical micrographs of extruded AZ31 Mg alloy sheets at different temperatures: a $563 \mathrm{~K}$, b $603 \mathrm{~K}$, c $643 \mathrm{~K}$, d $683 \mathrm{~K}$
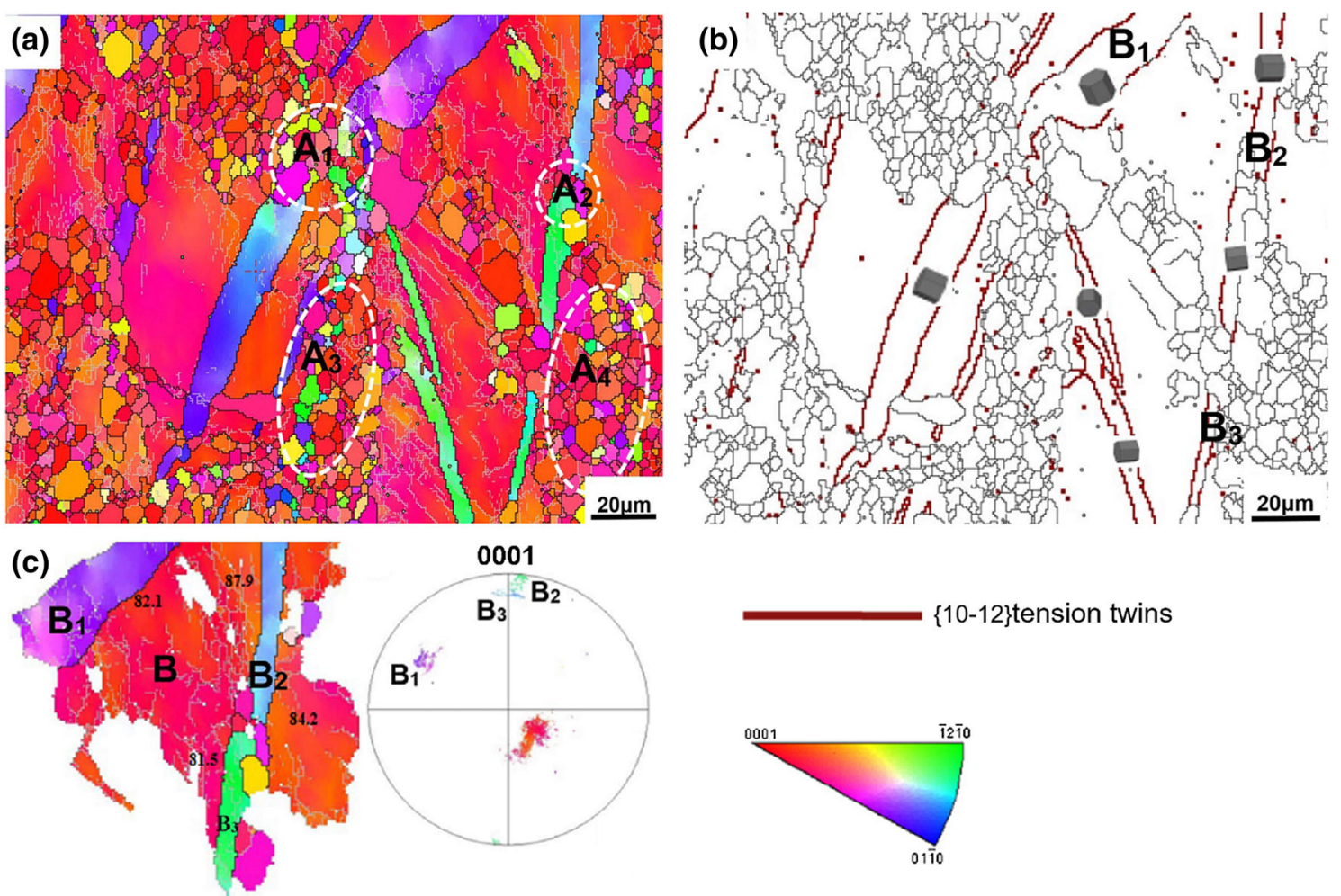

Fig. 4 EBSD observation results of extruded alloy sheets in the III zone at $563 \mathrm{~K}$ : a, c inverse pole figure maps, $\mathbf{b}$ twin distribution map 
in regions $\mathrm{A}_{3}$ and $\mathrm{A}_{4}$. From Fig. 4c, low-angle grain boundaries (LAGBs) can be observed within twins ( $B_{1}$ and $B_{3}$ ), which can be evolved into high-angle grain boundaries (HAGBs) to subdivide the twin during the subsequent deformation. Interestingly, the misorientations have significant difference among the $\{10-12\}$ tension twins, which will dramatically scatter the subsequent DRX orientation.

The inverse pole figures are shown in Fig. 5, and the samples exhibit a typical $<10-10>$ fiber texture with [10-10] orientation parallel to the extrusion direction (ED) (Fig. 5a). To further investigate the texture characteristics, a detailed analysis of the inverse pole figures for UnDRXed and DRXed regions in the III zone is carried out, as shown in Fig. 5b, c. Compared with the full region, a stronger basal texture with an intensity of 5.6 can be observed for the DRXed regions. As for the UnDRXed regions, although the basal texture is still dominated, its intensity becomes much weaker.

Figure 6 presents the inverse pole figure (IPF) map and LAGB distribution of Mg alloys sheet in IV zone at $563 \mathrm{~K}$, uniform DRX grains can be clearly observed, and the average grain size is measured to be about $7.4 \mu \mathrm{m}$. Compared with the Fig. 4a, the grain size is further refined after frustum shearing extrusion. Moreover, the twins and LAGBs are almost eliminated after hot extrusion, as presented in Fig. 6b. For further distinction DRX and UnDRX grains in Fig. 6c, we have marked them separately by EBSD technology. To examine the effect of DRX on the texture evolution, the full region, DRXed region and UnDRXed region are further analyzed through inverse pole figure in detail, as shown in Fig. 7. The basal texture dominates, but it is not the typical type; instead, the basal planes are inclined to some degrees with the ED (Fig. 7a). However, the UnDRXed region still exhibits the typical basal texture with intensity of 7.99, but there are only a few UnDRX grains in IV zone; therefore, it cannot affect the whole texture. The basal texture of DRXed region is similar to that of the full region; fortunately, the intensity is much weaker. Compared with Fig. 5, the texture is significantly changed. Therefore, we can conclude that this technique could change the basal texture and promote the grain refinement, which is beneficial to improving the ductility of $\mathrm{Mg}$ alloys at ambient temperature.

\subsection{Misorientation Angle}

The relative frequency of misorientation angle of $\mathrm{Mg}$ alloys at different zone is depicted in Fig. 8. From Fig. 8a, a large number of LAGBs appear in III zone, which agrees with a large amount of sub-grain boundaries emerged in the UnDRXed grains. Compared with the LAGBs, HAGBs are fewer in III zone, which means that the grains will be refined greatly in VI zone. As the deformation proceeds from III zone to VI zone, the fractions of LAGBs and HAGBs present a decreasing tendency and an increasing tendency, respectively, and the average misorientation transforms from $31.5^{\circ}$ to $44.6^{\circ}$, which can be attributed to the enhancement of dislocation migration ability and enhancement of LAGBs with the further extrusion deformation.

\subsection{Texture Evolution}

The orientation density figures (ODF) of $\mathrm{Mg}$ alloys sheet extruded at temperatures from 563 to $683 \mathrm{~K}$ are shown in Fig. 9. It is found that the Euler angles of the strongest orientation are $\left(45^{\circ}, 90^{\circ}, 0^{\circ}\right),\left(90^{\circ}, 90^{\circ}, 0^{\circ}\right),\left(90^{\circ}, 0^{\circ}, 30^{\circ}\right)$ and $\left(60^{\circ}, 0^{\circ}, 0^{\circ}\right)$ for $563 \mathrm{~K}, 603 \mathrm{~K}, 643 \mathrm{~K}$ and $683 \mathrm{~K}$, respectively, and their maximum intensities are 6.7, 7.8, 8.6 and 9.6, respectively. Besides, it should be noted that texture becomes more scattered at $683 \mathrm{~K}$ than that of other temperatures. As we all know, the critical resolved shear stress (CRSS) of slip systems is different under different temperature. The CRSS of slip systems is temperature dependent, the hindering effect of grain boundaries on the dislocation movement becomes weaker and a variety of slip systems are activated, which leads to the change finally in the texture orientation $[8,28]$. At room temperature, basal has significantly lower CRSS compared to prismatic and pyramidal. Hence, even if a particular orientation has higher Schmid factor for prismatic or pyramidal slip, still slip will take place on basal slip systems owing to lower CRSS. At high temperatures, the difference in CRSS between basal and other slip systems get reduced to some
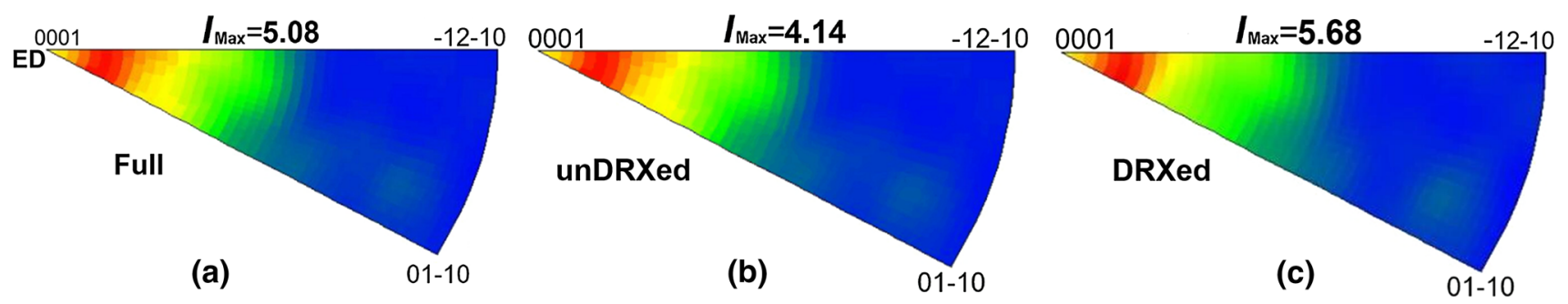

Fig. 5 IPFs of extruded AZ31 Mg alloy sheets in the III zone along the ED. $I_{\max }$ denotes the maximum texture intensity 

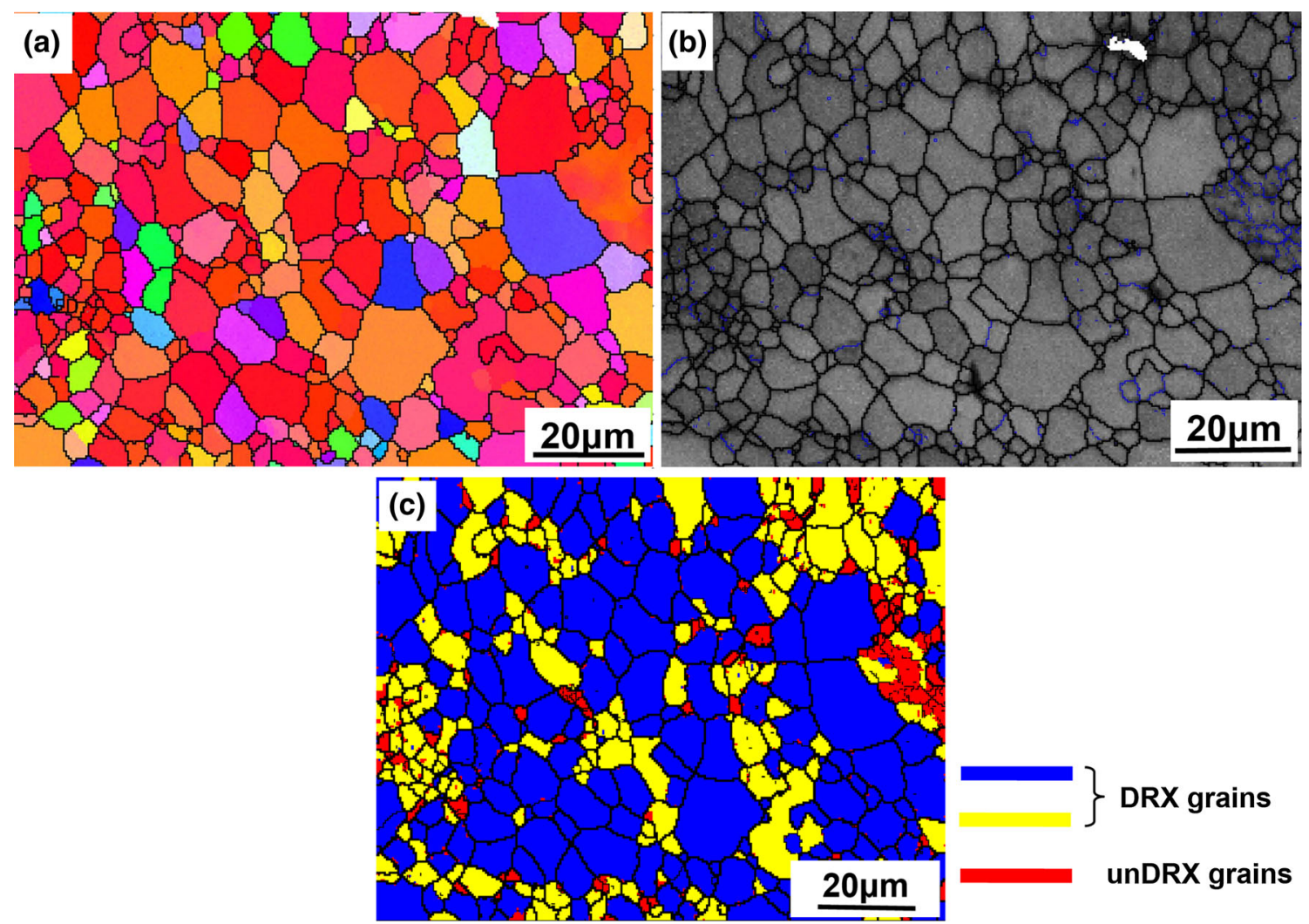

Fig. 6 EBSD observation results of extruded Mg alloy sheets in the IV zone at $563 \mathrm{~K}$ : a inverse pole figure map, b LAGB distribution diagram
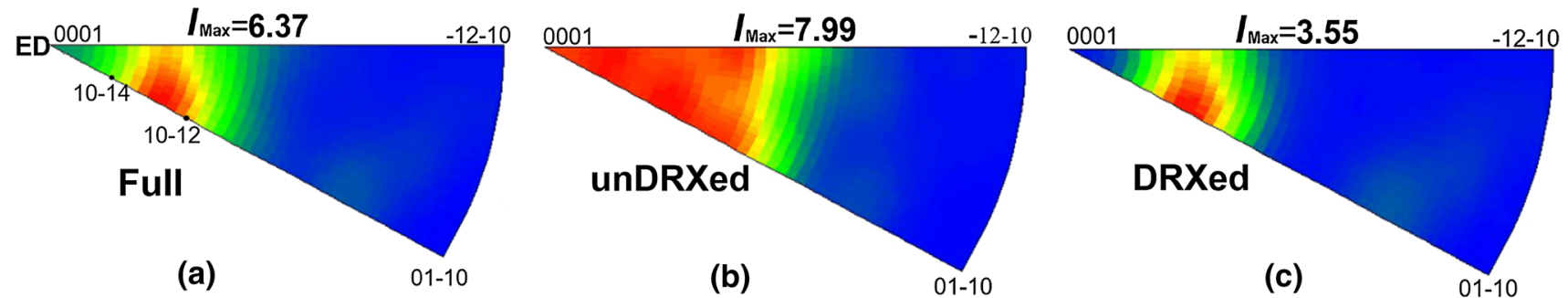

Fig. 7 IPFs of extruded Mg alloy sheets in the IV zone along the ED. $I_{\max }$ denotes the maximum texture intensity

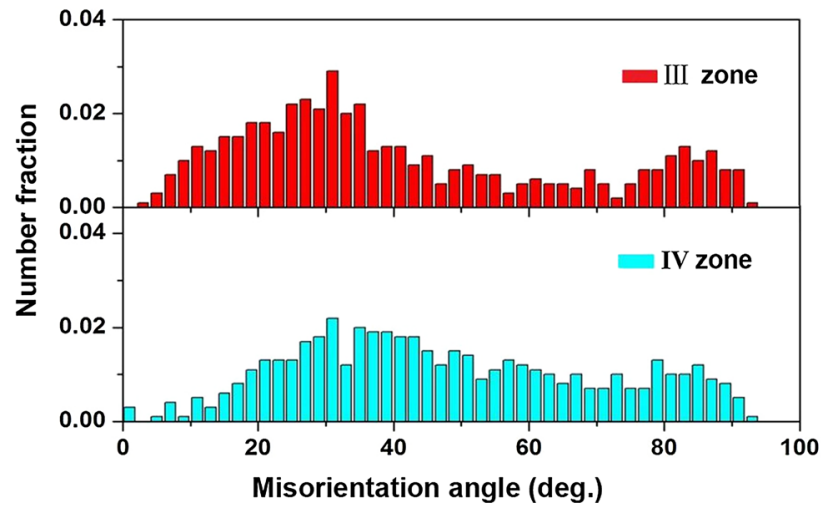

Fig. 8 Misorientation angle distribution of the Mg alloys sheets in different zones extent, and hence, there is always a possibility of activation of non-basal slip systems. Furthermore, in this work, when the billets were heated to the extrusion temperature, it is easy to take place static recovery and static recrystallization that produce small grains in the twin boundaries during the heat preservation process. With the increase in the heating temperature, the ability of static recrystallization and static recovery increases, and more small grains produce in the twin boundaries. Compared with coarse grains, it is difficult to start the basal slip for small grains during the extrusion process [29]. Therefore, the $\{0001\}$ basal slip becomes much stronger with increasing extrusion temperature.

The texture orientation density of AZ31 Mg alloy sheets at different extrusion temperatures is presented in Fig. 10. 

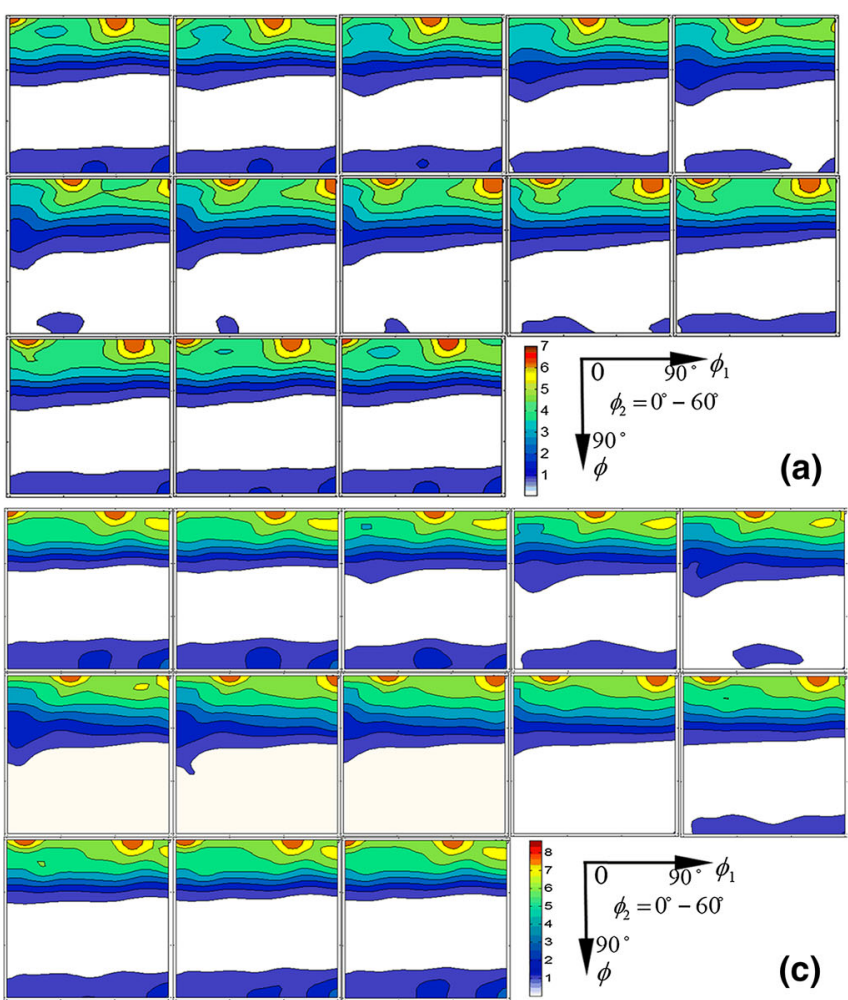

(c)

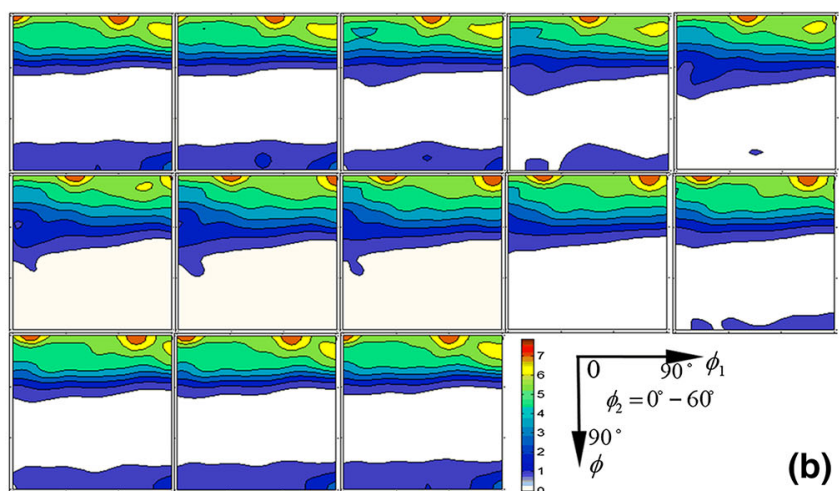

(b)

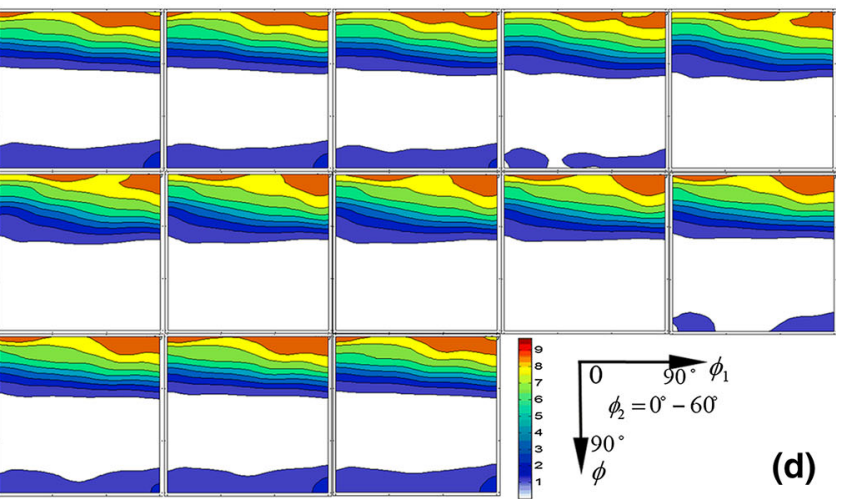

Fig. 9 ODF of extruded Mg alloys sheets at different temperatures: a $563 \mathrm{~K}$, b $603 \mathrm{~K}$, c $643 \mathrm{~K}$, d $683 \mathrm{~K}$

The extruded alloys sheets exhibit a typical extrusion texture [30, 31]. There are (0001)[1-210] and (0001)[10-10] basal textures formed in different extrusion temperatures. However, once the temperature exceeds $563 \mathrm{~K}$, a new texture (0001)[0-110] appears. It is confirmed that the texture intensity exhibits an increasing tendency with increasing extrusion temperature, as shown in Fig. 9, which is also reported by other researchers previously, explaining that the critical resolved shear stress decreases with the increase in deformation temperature, thus enhancing the activity of the prismatic slip and consequently strengthening the texture [32].

\subsection{Mechanical Properties}

Tensile properties of AZ31 Mg alloy sheets obtained from tensile tests are shown in Fig. 11. The yield strength and ultimate tensile strength of $\mathrm{Mg}$ alloys sheet can reach 189.6 MPa and 288.4 MPa at $563 \mathrm{~K}$, respectively. However, with the increase in extrusion temperature, the ultimate tensile strength decreases from 288.4 to $265.9 \mathrm{MPa}$, yield stress decreases from 189.6 to $130.7 \mathrm{MPa}$ and the elongation decreases from 24.9 to $21.5 \%$. The extruded AZ31 Mg alloy sheet in our research has a higher ultimate tensile strength at $563 \mathrm{~K}$, which can be reasonably explained on the basis of several factors. As we have already discussed, the refined and uniform DRX grains are obtained by the extrusion, which are beneficial to the improvement of the mechanical properties. According to the Hall-Petch relationship [28], the decreased mechanical property is mainly attributed to the grain coarsening. The average grain size of the $\mathrm{Mg}$ alloys sheet at $563 \mathrm{~K}$ is about $6.4 \mu \mathrm{m}$, while the average grain size at $683 \mathrm{~K}$ is about $12.6 \mu \mathrm{m}$. The yield stress of AZ31 Mg alloy extruded at $563 \mathrm{~K}$ is $189.6 \mathrm{MPa}$, which is much higher than those of $154 \mathrm{MPa}$ and $137 \mathrm{MPa}$ extruded once by the equal channel angular extrusion (ECAE) at $593 \mathrm{~K}$ and $493 \mathrm{~K}$ [33, 34], respectively. Furthermore, Tong et al. [35] have reported that the tensile strength was calculated as $220.3 \mathrm{MPa}$ in the alloys with extrusion ratio (ER) of 20:1 for indirect extrusion, but the ER was only 8.8 in our work and the ultimate tensile strength can be up to $288.4 \mathrm{MPa}$.

In addition, texture has a significant effect on the mechanical properties of the extruded specimens. As is well known, $\mathrm{Mg}$ has an hep structure, and the dislocation slip occurs mostly on the basal plane (0001) in $<1-210>$ direction, which leads to the development of a preferred orientation with the alignment of the $c$-axis perpendicular to the metal flow direction during extrusion processes $[36,37]$. At high temperatures, the difference in CRSS between the base and other sliding systems decreases to some extent, and it is very beneficial to the formation of other non-basal texture. For AZ31 Mg alloy sheet, different texture types imply a tendency to increase in the 

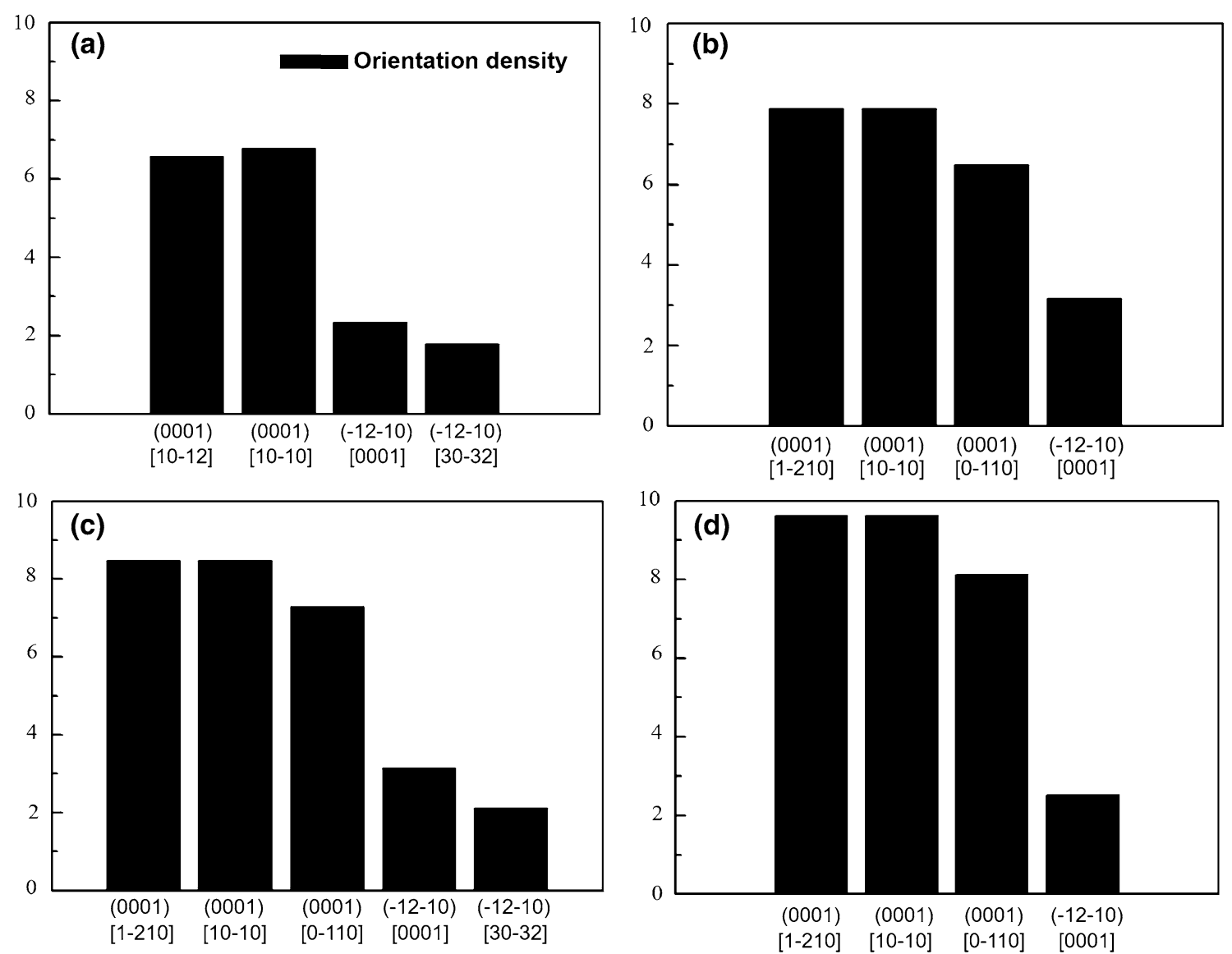

Fig. 10 Texture orientation density figures of extruded $\mathrm{Mg}$ alloys sheets at different temperatures: a $563 \mathrm{~K}$, b $603 \mathrm{~K}$, c $643 \mathrm{~K}$, d $683 \mathrm{~K}$

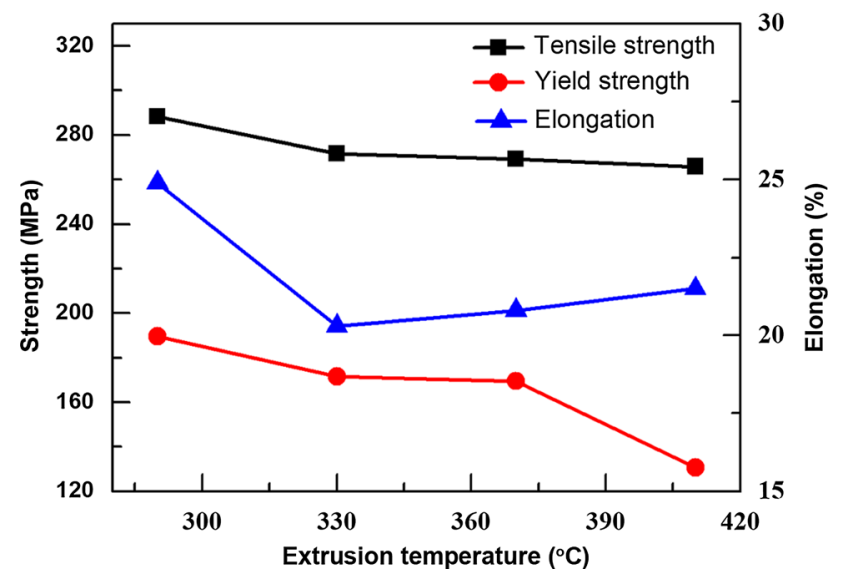

Fig. 11 Tensile stress-strain curves of extruded Mg alloys sheets at different temperatures: a $563 \mathrm{~K}$, b $603 \mathrm{~K}$, c $643 \mathrm{~K}, \mathbf{d} 683 \mathrm{~K}$

mechanical properties of sheet, which can coordinate the deformation and is beneficial to the improvement of stretch formability. From Fig. 9, the texture intensity increases to 8.13 with the increase in extrusion temperature, but the texture becomes more scattered. Therefore, we can conclude that the grain growth has a more important influence than texture weakening on mechanical properties.

\subsection{Tensile Fracture}

SEM images of the tensile fracture surface are shown in Fig. 12. From the fracture surface of AZ31 Mg alloys extruded at $563 \mathrm{~K}$ (Fig. 12a), the fracture feature reveals the occurrence of both cleavage facets and dimples. We can infer that it mainly belongs to the quasi-cleavage fracture. From Fig. 12b, a typical cleavage plane with a length exceeding $45 \mu \mathrm{m}$ can be observed clearly, indicating that the AZ31 Mg alloy sheet presents a relatively poor ductility, and the density and size of dimples are increased with the increase in extrusion temperature (Fig. 12c, d).

\section{Conclusions}

The effects of extrusion temperature on the microstructure, texture evolution, mechanical properties and strengthening mechanisms of the extruded AZ31 Mg alloys sheet are systematically studied. The main conclusions are summarized as follows:

(1) After extrusion, the grain size is greatly refined and the average grain size increases from 6.4 to $12.6 \mu \mathrm{m}$ 

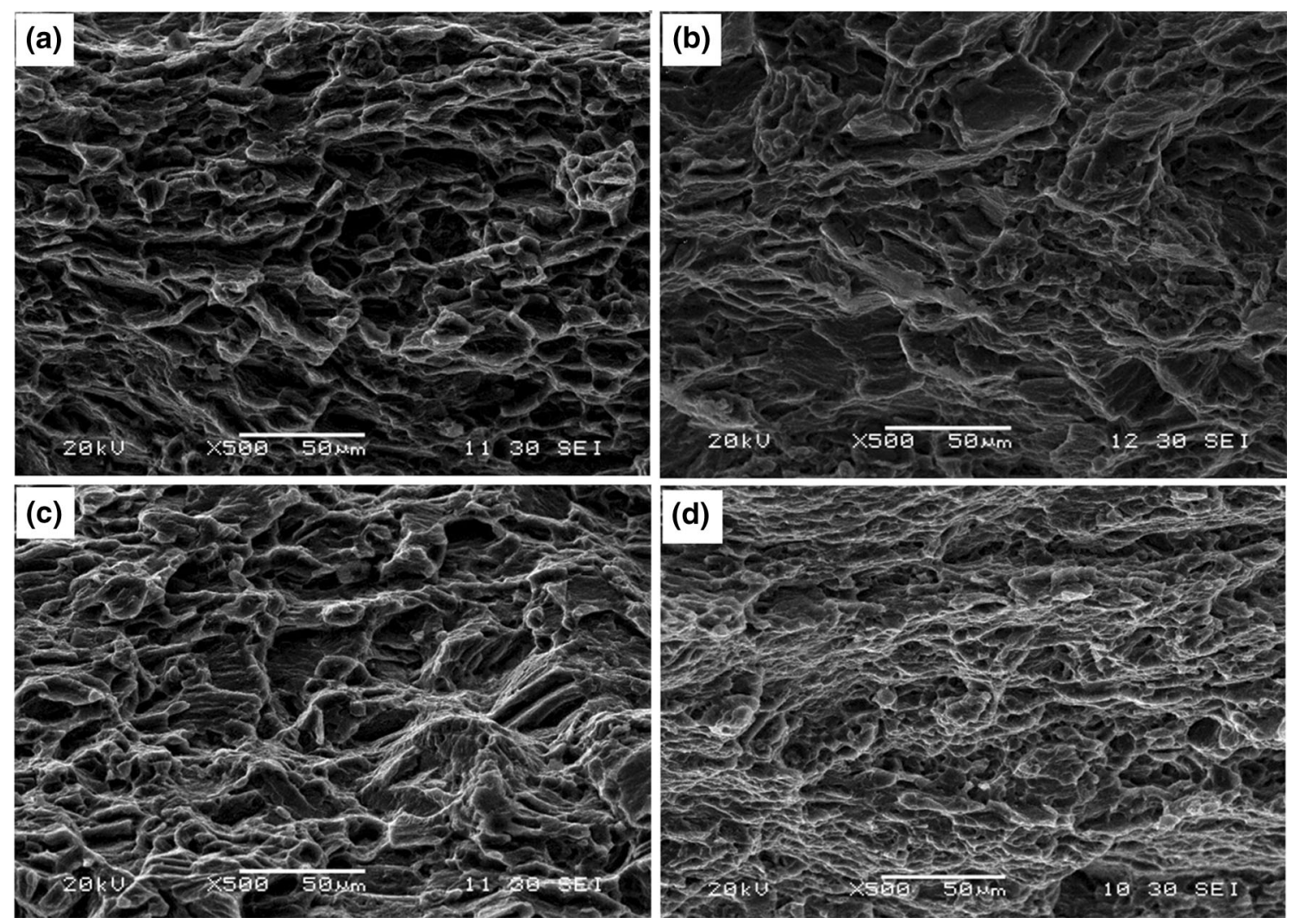

Fig. 12 Fracture morphology of extruded Mg alloys sheets at different temperatures: a $563 \mathrm{~K}$, b $603 \mathrm{~K}$, c $643 \mathrm{~K}$, d $683 \mathrm{~K}$

with increasing extrusion temperature. The $\mathrm{Mg}$ alloy extruded at $563 \mathrm{~K}$ shows the smallest and the most uniform grains.

(2) The pre-compression twinning plays an important role during the frustum shearing extrusion process. The die structure in the IV zone is conducive to further improve the grain size and texture of the AZ31 alloy. Besides, the pre-twinning and extrusion temperature are found to significantly influence the texture of the alloys.

(3) The extrusion temperature has an obvious effect on mechanical performances of the extruded $\mathrm{Mg}$ alloy. With the increase in extrusion temperature, the mechanical properties for the $\mathrm{Mg}$ alloys are worsened due to the combined effect of grain size and texture type. A good combination of strength and ductility is obtained for the alloy extruded at $563 \mathrm{~K}$, which shows the yield strength, tensile strength and elongation of 189.6 MPa, 288.4 MPa and 24.9\%, respectively.

Acknowledgements This work was partly supported by the National Natural Science Foundation of China (Grant Nos. 51505143 and 51704112), the Scientific Research Fund of Hunan Provincial Education Department (Grant No. 17B089) and the financial supports from the China Postdoctoral Science Foundation (Grant No. 2016T90759).

\section{References}

[1] F. Li, Y. Liu, X. Li, Acta Metall. Sin. (Engl. Lett.) 30, 1 (2017)

[2] R. Sun, Z.C. Wang, M. Saito, N. Shibata, Y. Ikuhara, Nat. Commun. 6, 7120-1 (2015)

[3] X.J. Wang, D.K. Xu, R.Z. Wu, X.B. Chen, Q.M. Peng, L. Jin, Y.C. Xin, Z.Q. Zhang, Y. Liu, X.H. Chen, G. Chen, K.K. Deng, H.Y. Wang, J. Mater. Sci. Technol. 34, 245 (2018)

[4] R.Z. Wu, Y.D. Yan, G.X. Wang, L.E. Murr, W. Han, Z.W. Zhang, M.L. Zhang, Int. Mater. Rev. 60, 65 (2015)

[5] Y.Z. Du, M.Y. Zheng, X.G. Qiao, K. Wu, X.D. Liu, G.J. Wang, X.Y. Lv, M.J. Li, X.L. Liu, Z.J. Wang, Y.T. Liu, Mater. Sci. Eng. A 583, 69 (2013)

[6] Y.Y. Guang, S.S. Yang, J.D. Wen, Scr. Mater. 43, 1009 (2016)

[7] S.H. Kang, Y.S. Lee, J.H. Lee, J. Mater. Process. Technol. 201, 436 (2008)

[8] Y. Wang, H. Choo, Acta Mater. 81, 83 (2014)

[9] Y.C. Xin, H. Zhou, H.H. Yu, R. Hong, H. Zhang, Q. Liu, Mater. Sci. Eng. A 622, 178 (2015)

[10] E. Mostaed, A. Fabrizi, D. Dellasega, F. Bonollo, M. Vedani, J. Alloys Compd. 638, 267 (2015)

[11] Z. Yu, C. Xu, J. Meng, X. Zang, S. Kamado, Mater. Sci. Eng. A 713, 234 (2018)

[12] J.S. Zhang, W.B. Zhang, L.P. Bian, W.L. Cheng, X.F. Niu, C.X. Xu, S.J. Wu, Mater. Sci. Eng. A 585, 268 (2013)

[13] F.M. Lu, A.B. Ma, J.H. Jiang, D.H. Yang, D. Song, Y.H. Yuan, J. Chen, Mater. Sci. Eng. A 594, 330 (2014) 
[14] T.T. Zhang, W.X. Wang, J. Zhou, X.Q. Cao, R.S. Xie, Y. Wei, Acta Metall. Sin. (Engl. Lett.) 10, 1 (2017)

[15] Q.H. Wang, J.F. Song, B. Jiang, A.T. Tang, Y.F. Chai, T.H. Yang, G.S. Huang, F.S. Huang, Mater. Sci. Eng. A 720, 85 (2018)

[16] J. Xu, J.F. Song, B. Jiang, J.J. He, Q.H. Wang, B. Liu, G.S. Huang, F.S. Pan, Mater. Sci. Eng. A 706, 172 (2017)

[17] J. Xu, T.H. Yang, B. Jiang, J.F. Song, J.J. He, Q.H. Wang, Y.F. Chai, G.S. Huang, F.S. Pan, J. Alloys Compd. 762, 719 (2018)

[18] C. Wang, H. Ding, B.S. Wang, K. Wang, J.J. Shi, J.F. Chen, Acta Metall. Sin. (Engl. Lett.) 30, 921 (2017)

[19] M.J. Hou, H. Zhang, J.F. Fan, Q. Zhang, L.F. Wang, H.B. Dong, B.S. Xu, J. Alloys Compd. 15, 514 (2018)

[20] L. Jiang, J.J. Jonas, A.A. Luo, A.K. Sachdev, S. Godet, Mater. Sci. Eng. A 445, 302 (2007)

[21] S.G. Hong, S.H. Park, S.L. Chong, Acta Mater. 18, 5873 (2010)

[22] A. Galiyev, R. Kaibyshev, G. Gottstein, Acta Mater. 7, 1199 (2001)

[23] F. Chai, D. Zhang, Y. Li, W. Zhang, J. Mater. Sci. 8, 3212 (2015)

[24] M.P. Liu, H.J. Roven, M.Y. Murashkin, R.Z. Valiev, A. Kilmametov, Z. Zhang, Y.D. Yu, J. Mater. Sci. 13, 4681 (2013)

[25] Q.S. Yang, B. Jiang, Z.J. Yu, Q.W. Dai, S.Q. Luo, Acta Metall. Sin. (Engl. Lett.) 28, 1257 (2015)
[26] A.B. Spierings, K. Dawson, T. Heeling, P.J. Uggowitzer, R. Schaublin, F. Palm, K. Wegener, Mater. Des. 115, 52 (2017)

[27] X. Huang, Y. Chino, M. Yuasa, H. Ueda, M. Inoue, F. Kido, T. Mastumoto, Mater. Sci. Eng. A 679, 162 (2017)

[28] Y.Z. Du, X.G. Qiao, M.Y. Zheng, K. Wu, S.W. Xu, Mater. Sci. Eng. A 620, 164 (2015)

[29] A. Kula, C.J. Silva, M. Niewczas, J. Alloys Compd. 727, 642 (2017)

[30] H.Y. Wu, M.D. Tzou, C.C. Huang, H.H. Tsai, Int. J. Adv. Manuf. Technol. 80, 1241 (2015)

[31] B. Kim, S.M. Baek, J.G. Lee, S.S. Park, J. Alloys Compd. 706, 56 (2017)

[32] H.Y. Chao, Y. Yang, X. Wang, E.D. Wang, Mater. Sci. Eng. A 528, 3428 (2011)

[33] C.W. Su, L. Lu, M.O. Lai, Mater. Sci. Eng. A 434, 227 (2006)

[34] H.K. Kim, W.J. Kim, Mater. Sci. Eng. A 385, 300 (2004)

[35] L.B. Tong, M.Y. Zheng, L.R. Cheng, S. Kamado, H.J. Zhang, Mater. Sci. Eng. A 569, 48 (2013)

[36] Y. Yang, X.D. Peng, H.M. Wen, G.B. Wei, W.D. Xie, E.J. Lavernia, Mater Sci. Eng. A 611(1), 8 (2014)

[37] S.H. Park, S.H. Kim, H.S. Kim, J. Yoon, B.S. You, J. Alloys Compd. 667, 170 (2016) 